\title{
Linking baseflow separation and groundwater storage dynamics in an alpine basin (Dammagletscher, Switzerland)
}

\author{
F. Kobierska ${ }^{1,2}$, T. Jonas ${ }^{1}$, J. W. Kirchner ${ }^{3,4}$, and S. M. Bernasconi ${ }^{2}$ \\ ${ }^{1}$ WSL Institute for Snow and Avalanche Research SLF, Davos, Switzerland \\ ${ }^{2}$ Geological Institute, ETH Zurich, Sonnegstrasse 5, 8092 Zürich, Switzerland \\ ${ }^{3}$ Department of Environmental Systems Science, ETH Zurich, Universitaetstrasse 22, 8092 Zürich, Switzerland \\ ${ }^{4}$ Swiss Federal Research Institute WSL, Zürcherstrasse 111, 8903 Birmensdorf, Switzerland \\ Correspondence to: F. Kobierska (fbaffie@gmail.com)
}

Received: 24 September 2014 - Published in Hydrol. Earth Syst. Sci. Discuss.: 3 November 2014

Revised: 31 July 2015 - Accepted: 4 August 2015 - Published: 25 August 2015

\begin{abstract}
This study aims at understanding interactions between stream and aquifer in a glacierized alpine catchment. We specifically focused on a glacier forefield, for which continuous measurements of stream water electrical conductivity, discharge and depth to the water table were available over 4 consecutive years. Based on this data set, we developed a two-component mixing model in which the groundwater component was modelled using measured groundwater levels. The aquifer actively contributing to streamflow was assumed to be constituted of two linear storage units. Calibrating the model against measured total discharge yielded reliable sub-hourly estimates of discharge and insights into groundwater storage properties. Our conceptual model suggests that a near-surface aquifer with high hydraulic conductivity overlies a larger reservoir with longer response time.
\end{abstract}

\section{Introduction}

Groundwater (GW) storage dynamics in alpine catchments are difficult to determine but could influence the response of mountain hydrology to climate change. A better understanding of stream-aquifer interactions is therefore necessary to predict hydrological flow patterns in the future. Alpine sites put additional constraints on data acquisition because snow cover, weather conditions, and/or rough terrain limit the available measurements.

In this study, we estimate groundwater storage dynamics in the alpine headwater catchment fed by the Damma Glacier in central Switzerland. In previous studies, we fo- cused on local properties of the groundwater flow in specific stream reaches (Magnusson et al., 2014; Kobierska, 2014). The aim is now to use this specific knowledge to upscale our hydrogeological understanding to the whole glacier forefield. We seek to estimate the contribution of groundwater and hyporheic exchange to streamflow during different periods of the year, as well as the volume and response times of groundwater storage.

The topic of contributing storage to streamflow has been covered by many studies. Analytical and numerical formulations of the Boussinesq equation (e.g. Brutsaert and Nieber, 1977; Rupp and Selker, 2006; Rupp et al., 2009) and linear or non-linear reservoirs (e.g. Wittenberg and Sivapalan, 1999; Hannah and Gurnell, 2001; Majone et al., 2010) have been explored. At our site, traditional recession analysis is challenged by the fact that discharge is dominated by the diurnal dynamics of snow and glacier melt. Pure recession events are therefore very rare.

In alpine sites, mixing models based on natural tracers are a typical avenue for hydrograph separation (i.e. Hinton and Schiff, 1994; Liu et al., 2004; Covino and McGlynn, 2007; Blaen et al., 2014). Dzikowski and Jobard (2012) used electrical conductivity (EC) data to estimate the groundwater contribution to the discharge of an alpine stream. They defined seasonal ranges in the relationship between EC and streamflow rather than predicting groundwater flow and total flow for individual time steps. On the other hand, Covino and McGlynn (2007) presented groundwater table data but did not use them in their mixing model. 
We suggest here a different approach to using mixing models with stream water EC data, which involves a time-varying groundwater input. We implemented a two-component mixing model (glacier melt and groundwater) in which the groundwater exfiltration component is the output of two linear groundwater reservoirs. One reservoir provides a baseflow component. The second reservoir models additional groundwater using five groundwater stage measurements throughout the forefield. In the following, we refer to infiltration as the flow from the stream into the aquifer (i.e. aquifer recharge) and to exfiltration as the flow of groundwater and hyporheic exchanges back into the stream (i.e. aquifer discharge).

To verify the robustness of the model and to understand the influence of each data input taken separately (EC or GW stage data), we compared our calibrated model to two partial models, each of which held one measured input variable (stream water electrical conductivity or groundwater level) constant. By further analysing groundwater interactions (infiltration and exfiltration) with stream water, we (1) verify that groundwater exfiltration estimates are realistic, (2) provide an upper limit to the volume of the active groundwater reservoir, and (3) conclude with a conceptual representation of the forefield's main hydrogeologic features.

\section{Study site and experimental methods}

\subsection{Site description}

The Damma Glacier forefield (Fig. 1) is part of a small $\left(10.7 \mathrm{~km}^{2}\right)$ granitic catchment situated in the central Swiss Alps. It is currently being studied as part of the SoilTrEC project (Soil Transformations in European Catchments; Bernasconi et al., 2011). The glacier covers $40 \%$ of the catchment and has been retreating since the end of the Little Ice Age (LIA). Due to a sharp change in slope gradient, a small piece of the glacier has become detached from the main glacier during its retreat and is referred to as the "dead ice body". Large lateral moraines date from approximately 1850 (the end of the LIA) and two terminal moraine bands dating from 1927 and 1992 mark the end of two short periods of re-advance. The elevation of the catchment ranges from 1800 to $3600 \mathrm{~m}$ a.s.l. and the entire catchment is covered by snow approximately 6 months per year.

The glacier forefield itself ranges from 1800 to $2000 \mathrm{~m}$ a.s.l. and covers an area of approximately $0.5 \mathrm{~km}^{2}$. The average annual temperature between November 2008 and November 2012 was $2.2^{\circ} \mathrm{C}$ at our automatic weather station (AWS) in the forefield (see Fig. 1). In 2008, annual precipitation and evapotranspiration for the whole catchment were estimated at 2300 and $70 \mathrm{~mm}$, respectively (Kormann, 2009). With a yearly cumulative discharge of approximately $2700 \mathrm{~mm}$, the water balance of the catchment is clearly posi-

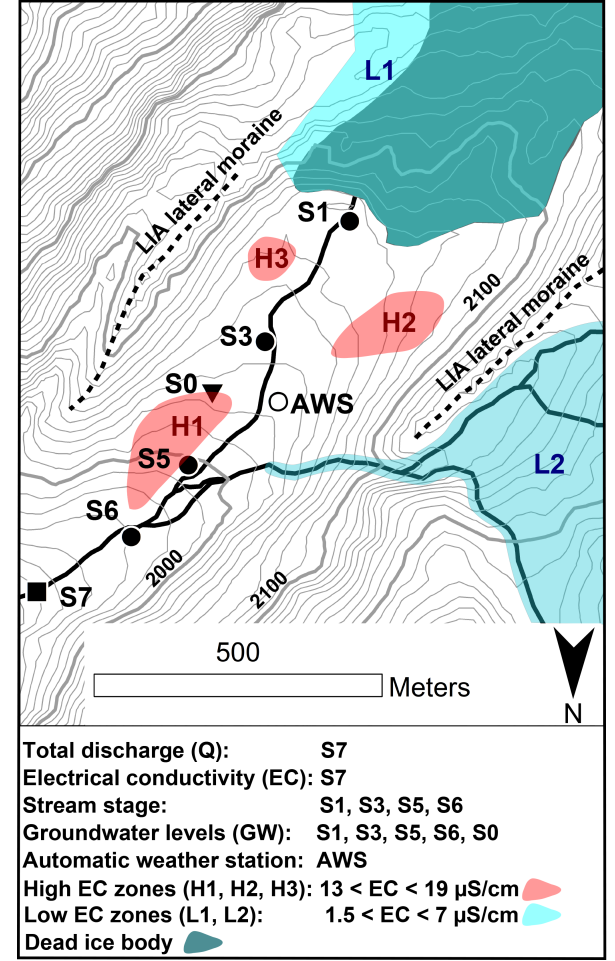

Figure 1. The Damma Glacier forefield. At sites S1, S3, S5 and S6 (solid circles), stream and groundwater levels are recorded. At site S7 (solid square), stream stage is measured for total discharge. At site S8 (solid triangle), only one piezometer is installed. Colour patches indicate zones of high (H1, H2 and H3) and low (L1, L2) electrical conductivity. An automatic weather station (AWS) is located in the middle of the forefield. Lateral moraines are indicated with dashed black lines and terrain elevation is shown by $10 \mathrm{~m}$ contour intervals (figure adapted from Magnusson et al., 2014).

tive and corresponds to an average glacier mass loss of about $1 \mathrm{~m}$ depth per year.

The basin is characterized by heavy snowfall in winter, making discharge difficult or impossible to measure. Discharge becomes dominated by baseflow as snow and glacier melt gradually cease in late autumn. In late spring (typically end of May), snowmelt leads to a strong increase in discharge and a clear daily cycle is quickly established. In autumn, daily cycles of glacier melt are interrupted by rain events and the recession of a slow-draining aquifer becomes noticeable as melt rates decrease.

The forefield is encompassed by two steep lateral moraines (Fig. 1). The area in the vicinity of S3 is composed of a relatively impermeable silty surface layer, which leads to surface runoff during storms, as evidenced by scouring of the surface (see Fig. 2 in Kobierska et al., 2015). The area between S5 and S0, where the topography suddenly steepens, is rich in springs, which display seemingly constant flows (in the order of $10 \mathrm{~L} \mathrm{~s}^{-1}$ per spring) during the summer season. 


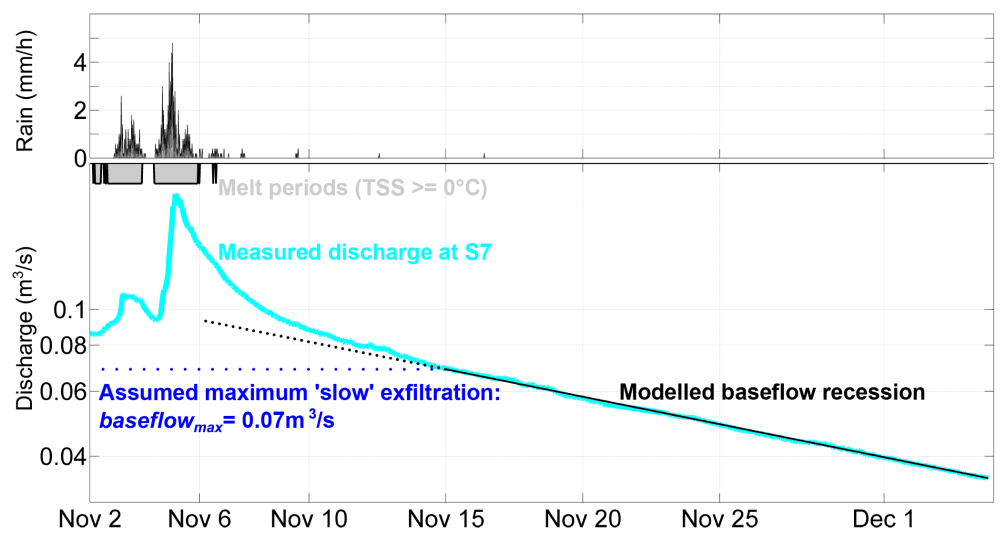

Figure 2. Baseflow recession during November 2008. The lower panel shows measured and modelled discharge at S7 on a logarithmic scale. The dotted black line illustrates how the modelled baseflow recession diverges from measured discharge before 15 November. Note that melting periods (non-negative temperature of snow surface) are indicated as grey shaded bars. The upper panel plots successive rain events.

Magnusson et al. (2014) studied four groundwater transects (S1, S3, S5 and S6 in Fig. 1). Each transect was equipped with three pressure transducers: one in the stream and two in piezometric tubes placed on a line perpendicular to the stream. Taking S1 as an example, we adopted the following notation: $\mathrm{S} 1_{\text {stream }}$ for the stream stage measurement, $\mathrm{S} 1_{\text {near }}$ for the piezometer that is closer to the stream, and $S 1_{\text {far }}$ for the piezometer farther away from the stream. Note that $\mathrm{S} 0$ consists of one single piezometer located approximately $50 \mathrm{~m}$ from the main stream channel (Fig. 1). Due to difficult field conditions, the piezometers could only be installed to a maximum depth of $1.5 \mathrm{~m}$.

The water table is driven by stronger gradients along the stream than towards it. This results in strong advection in the direction of streamflow, as shown in Kobierska et al. (2015). The mean gradient between S1 and S7 is $13.5 \%$ over a distance of $840 \mathrm{~m}$. Between S0 and S5, the steepest section of the forefield has gradients of over $20 \%$ for approximately $150 \mathrm{~m}$. Near-stream lateral groundwater gradients are primarily influenced by diurnal stream stage fluctuations rather than by topography-driven longitudinal gradients (Magnusson et al., 2014).

This paper focuses on the dynamics of the active groundwater storage, which is the part of the aquifer that can exfiltrate into the stream before it reaches the gauging station. Refraction seismics and electrical resistivity surveys were carried out on four transects of the forefield (Kobierska, 2014). These geophysical studies suggest that the saturated glacial till does not contain permafrost areas over the whole forefield. The sediment layer should also be at least $10 \mathrm{~m}$ thick in much of the forefield, including the vicinity of the discharge station. This means that an important part of the aquifer in the forefield is "non-contributing", meaning that not all water flowing out of the catchment is measured at the discharge station. The lack of permafrost means that changes in groundwater levels reflect changes in groundwater volumes (rather than a change in the lower boundary due to permafrost melting).

\subsection{Hydrometeorological data}

Groundwater levels were measured with Hobo U20 Water Level Loggers (5 min sampling intervals averaged to $30 \mathrm{~min}$ values) at S1, S3, S5 and S6 as shown in Fig. 1. The method is described in detail in Magnusson et al. (2014). Stream stage was measured at the catchment outlet (S7 in Fig. 1), using both a cable-supported radar device and a pressure logger installed in a partly perforated tube. The rating curve of discharge as a function of stream level was calibrated with the results of salt and dye tracer dilution tests across a wide range of flows (35-4500 $\mathrm{L} \mathrm{s}^{-1}$, see Magnusson et al. (2012) for further details). According to the manufacturer's specification, the loggers have $0.14 \mathrm{~cm}$ resolution and $0.3 \mathrm{~cm}$ accuracy. The absolute pressure readings were adjusted for atmospheric pressure variations (measured at site S7) also using a Hobo U20 pressure sensor.

Table 1 presents values of the main hydrometeorological parameters for successive winters and summers (taken from start of June to end of October), as measured by the discharge station and the meteorological station (S7 and AWS in Fig. 1). This highlights the succession of hydroclimatically different years, which presented a good opportunity to test the robustness of the model.

For example, Table 1 shows large year-to-year variability in snow water equivalent (SWE) and annual rainfall, and also shows that neither water source strongly dominates the water balance. SWE was estimated from the maximum snow depth of each winter, assuming a density of 0.3 . Snow depth was measured at the AWS with a Campbell Scientific SR50 ultrasonic sensor. Cumulated rainfall is calculated from rainfall measured at the AWS. Note that both SWE and rainfall data were measured at the AWS in the forefield and are thus not representative of the water input to the whole catchment 
which extends $1800 \mathrm{~m}$ above the forefield. Cumulated discharge also contains a significant ice melt component, which was not estimated in this study.

\subsection{Electrical conductivity endmembers}

Stream water EC and temperature were measured at the main runoff station (S7) with a WTW Tetracon 325 sensor (accuracy $0.5 \%$ for $\mathrm{EC}, 0.5^{\circ} \mathrm{C}$ for temperature under $15^{\circ} \mathrm{C}$ ). The 10 min sampling rate was averaged to 30 min values for this study. Various measurements of groundwater springs were also carried out throughout the forefield with a handheld WTW Cond 315i device (same accuracy) in order to determine endmember values for use in the mixing model. Continuous EC measurements of groundwater and stream water are also available for summer 2011 at three transects (S1, S3 and S5) and at some springs between S5 and S0. EC was temperature-corrected using a non-linear correction to a reference of $20^{\circ} \mathrm{C}$.

From those measurements, an electrical conductivity map of the forefield can be sketched (Fig. 1) with six geographically distinct areas (all displayed in Fig. 6). Zones L1, L2, $\mathrm{H} 1, \mathrm{H} 2$ and $\mathrm{H} 3$ serve as a visual representation of low and high EC zones based on 238 single EC measurements (Table 2) and previous work by Tresch (2007) at this site. Only the endmember EC values impact our model and not the extent of those zones. Naturally, the ruggedness of the field site did not allow measuring groundwater and glacier melt electrical conductivities everywhere in the forefield.

Between 2009 and 2012, EC measured at the main runoff station (S7) varied from 2 to $13.3 \mu \mathrm{S} \mathrm{cm}^{-1}$ with an average value of $6.6 \mu \mathrm{S} \mathrm{cm}^{-1}$. The main section of the stream through the forefield is fed by two glacial sub-catchments of low EC (areas L1 and L2, lower end only). Direct measurements of glacier melt on the dead ice body yielded EC values ranging from 1.7 to $2.1 \mu \mathrm{S} \mathrm{cm}^{-1}$. We use the lowest $\mathrm{EC}$ value measured for melting ice $\left(1.7 \mu \mathrm{S} \mathrm{cm}^{-1}\right)$ as the endmember value for glacier melt. EC can be assumed to be a conservative tracer in open-channel flow because of the short travel time of surface runoff through the forefield (on the order of $10 \mathrm{~min}$ ). This is confirmed by the low EC values (minimum of $2 \mu \mathrm{S} \mathrm{cm}^{-1}$ ) measured at the discharge station during extreme flow events.

Three distinct zones are rich in springs (areas H1, H2 and $\mathrm{H} 3$ ) and consistently present conductivities between 13 and $18 \mu \mathrm{S} \mathrm{cm}^{-1}$ (Table 2). These groundwater exfiltration zones average $15.1 \mu \mathrm{S} \mathrm{cm}^{-1}$ and show very little temporal variability, as captured by continuous data-logger measurements for summer 2011 in the upper part of H1. We can therefore confidently attribute an endmember value of approximately $15.1 \mu \mathrm{S} \mathrm{cm}^{-1}$ to groundwater exfiltration in the forefield.

\section{Models}

\subsection{Two-component mixing model}

In the previous section we found that EC displayed two distinct endmembers: groundwater at $15.1 \mu \mathrm{S} \mathrm{cm}^{-1}$ and glacier melt at $1.7 \mu \mathrm{S} \mathrm{cm}^{-1}$. As stream water EC was consistently anticorrelated to runoff, we considered using mixing models to study the relationship between EC and discharge at the basin scale.

Our modelling approach requires a set of specific assumptions.

1. The EC measured at the main discharge station is the result of pure mixing between glacier melt and groundwater exfiltration into the stream.

2. Glacier melt has a constant $\mathrm{EC}$ of $\mathrm{EC}_{\mathrm{gl}}=1.7 \mu \mathrm{S} \mathrm{cm}^{-1}$ (the lowest $\mathrm{EC}$ value measured for melting ice on the dead ice body).

3. Exfiltrating groundwater has a constant EC of $\mathrm{EC}_{\mathrm{gw}}=15.1 \mu \mathrm{S} \mathrm{cm}^{-1}$ (average of all groundwater measurements)

The first assumption of pure two-component mixing is violated when rain falls. Several rain events affected both discharge and EC signals during the study period. Because quantifying rainfall throughout the forefield and its impact on stream water EC was not the aim of this study, we excluded all periods when more than $2 \mathrm{~mm}$ of cumulated rain had fallen in the last $5 \mathrm{~h}$. This filter was designed to exclude the direct increase in surface runoff associated with rainfall events but not the subsequent exfiltration of rainwater that had infiltrated the aquifer. The filter threshold of $2 \mathrm{~mm}$ per $5 \mathrm{~h}$ is similar to typical melt rates and led to removing $10.8 \%$ of the data. The deleted time periods can be seen as gaps in the EC data (upper panel in Fig. 3).

The second assumption is best met in midsummer when meltwater runoff is dominated by glacier melt. The model does not differentiate snowmelt from glacier melt, as the same low endmember value $\mathrm{EC}_{\mathrm{gw}}$ is used.

Finally, the third assumption is justified by continuous EC measurements at several groundwater springs, which have shown that EC is reasonably constant in time (previous section).

In summary, the three assumptions outlined above lead to the following equations:

$$
\begin{aligned}
& Q(t)=Q_{\mathrm{gw}}(t)+Q_{\mathrm{gl}}(t), \\
& Q(t) \cdot \mathrm{EC}(t)=Q_{\mathrm{gw}}(t) \cdot \mathrm{EC}_{\mathrm{gw}}+Q_{\mathrm{gl}}(t) \cdot \mathrm{EC}_{\mathrm{gl}},
\end{aligned}
$$

where $Q(t)$ is total discharge at time $t, \mathrm{EC}_{\mathrm{gw}}$ and $\mathrm{EC}_{\mathrm{gl}}$ are respectively the groundwater and glacier electrical conductivity endmember values, and $Q_{\mathrm{gw}}(t)$ is the groundwater exfiltration flow whose modelling will be presented in the next 
Table 1. Key hydrometeorological parameters of the catchment measured at the AWS and the main discharge station (S7, discharge only). Values in millimetres were calculated using a catchment area of $10.7 \mathrm{~km}^{2}$. The start date for winter marks the establishment of a persistent snowpack at the AWS.

\begin{tabular}{lllccccc}
\hline Winter & $\begin{array}{l}\text { Start } \\
\text { date }\end{array}$ & $\begin{array}{l}\text { Peak } \\
\text { SWE } \\
\text { date }\end{array}$ & $\begin{array}{l}\text { Max } \\
\text { SWE } \\
(\mathrm{mm})\end{array}$ & $\begin{array}{c}\text { Summer } \\
(1 \mathrm{Jun}- \\
\text { 1 Nov })\end{array}$ & $\begin{array}{c}\text { Average } \\
\text { temperature } \\
\left({ }^{\circ} \mathrm{C}\right)\end{array}$ & $\begin{array}{c}\text { Cumulated } \\
\text { rainfall at } \\
\text { AWS (mm) }\end{array}$ & $\begin{array}{c}\text { Cumulated } \\
\text { discharge } \\
\text { at S7 (mm) }\end{array}$ \\
\hline $2008 / 2009$ & 29 Oct & 29 Apr & 828 & 2009 & 8.1 & 544 & 2157 \\
$2009 / 2010$ & 3 Nov & 5 Apr & 525 & 2010 & 7.6 & 598 & 1995 \\
$2010 / 2011$ & 8 Nov & 20 Mar & 408 & 2011 & 8.1 & 674 & 2344 \\
$2011 / 2012$ & 5 Dec & 25 Apr & 657 & 2012 & 8.7 & 764 & 2269 \\
\hline
\end{tabular}

Table 2. Results of EC measurements $\left(\mu \mathrm{S} \mathrm{cm}^{-1}\right)$ in the forefield. The zones refer to those drawn in Figs. 1 and 6.

\begin{tabular}{lrrlcr}
\hline Zone & Average & Min & Max & $\begin{array}{r}\text { Standard } \\
\text { deviation }\end{array}$ & $\begin{array}{r}\text { No. of } \\
\text { samples }\end{array}$ \\
\hline H1 & 15.5 & 12.8 & 18.3 & 1.2 & 89 \\
H2 & 12.7 & 10.9 & 14 & 1.2 & 15 \\
H3 & 15.4 & 13.6 & 17.8 & 1.3 & 13 \\
H1 + H2 + H3 & 15.1 & 10.9 & 18.3 & 1.5 & 117 \\
Rain & 6.1 & 4.3 & 7.5 & 1.3 & 4 \\
\hline
\end{tabular}

section. $Q_{\mathrm{gl}}$ is not modelled explicitly, but instead is estimated by end-member mixing analysis. Mathematically, $Q_{\mathrm{gl}}$ is eliminated when we combine Eqs. (1) and (2) to form Eq. (3):

$Q(t)=\frac{\left(\mathrm{EC}_{\mathrm{gw}}-\mathrm{EC}_{\mathrm{gl}}\right) \cdot Q_{\mathrm{gw}}(t)}{\mathrm{EC}(t)-\mathrm{EC}_{\mathrm{gl}}}$.

\subsection{Groundwater exfiltration model}

\subsubsection{Preliminary simulation considerations}

Our preliminary simulations considered groundwater exfiltration as the output of a non-linear storage model using two parameters (Wittenberg and Silvapalan, 1999). They were difficult to optimize due to equifinality problems because multiple parameter combinations led to similar calibration results and thus no clear optimum could be found.

Other problems arose because the piezometers had to be rather short due to the difficulties of installation in this environment. Thus, most of the piezometers dried up while the stream was still flowing. A realistic groundwater model for this catchment should therefore account for slow drainage of the aquifer in winter. In addition, as previously discussed in Magnusson et al. (2014), the piezometers provided important information on the daily near-surface interactions with the stream.

To avoid equifinality problems and account for both baseflow and shallower groundwater exchanges, we decided to introduce both a "slow" and a "fast" linear reservoir that could be calibrated separately. Accordingly, groundwater ex-

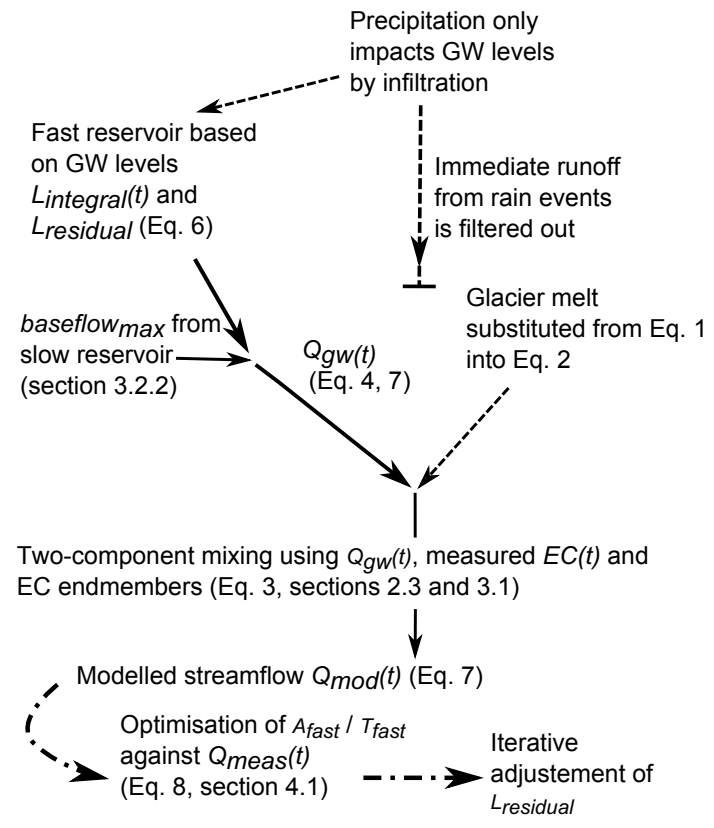

Figure 3. Schematic flow chart summarizing the functioning of the "FULL" model.

filtration is the sum of each reservoir's output, which is a linear function of storage volume as in Eq. (4):

$Q_{\mathrm{gw}}(t)=\frac{V_{\text {slow }}(t)}{T_{\text {slow }}}+\frac{V_{\text {fast }}(t)}{T_{\text {fast }}}$,

where the proportionality factor $T$ is the response time constant of the reservoir ( $T_{\text {slow }}$ or $\left.T_{\text {fast }}\right)$ and $V(t)$ is the current storage volume in each reservoir $\left(V_{\text {slow }}\right.$ or $\left.V_{\text {fast }}\right)$.

At the end of winter, the piezometers are empty and snowmelt initially fills the "slow reservoir". Our conceptual model considers that the "fast" reservoir only starts filling when the "slow" reservoir is full. The "slow" reservoir then remains full by receiving a constant inflow from the "fast" reservoir or the lateral moraines, and in turn providing an equal exfiltration flow (denoted baseflow max $_{\text {in }}$ the next section). How the two reservoirs precisely interact is not modelled. At the end of the season, when the "fast" reservoir is 
empty, the "slow" reservoir no longer receives flow inputs and its storage starts to decrease.

\subsubsection{Slow linear reservoir}

We calibrated $T_{\text {slow }}$ with a recession event at the end of 2008 , which was the only pure recession event lasting more than 2 weeks with reasonable discharge amplitude. In all other years, continuous measurements ended too early due to disturbances from snow loads and icing in the river channel. In 2008, the autumn was marked by an early big snow storm after which snow cover persisted into winter. Snow covered the whole forefield but had no effect on the stream geometry, such that the subsequent stage measurements were not affected by snow loads. Pure recession was established because the thick snow cover was efficient in stopping glacierand snowmelt, even during some short warm periods that followed. Based on Eq. (4), the recession hydrograph can be fitted using Eq. (5):

$$
Q_{\text {recession }}(t)=Q_{\text {meas }}\left(t_{\text {end }}\right) \cdot \exp \left(\frac{\left(t_{\text {end }}-t\right)}{T_{\text {slow }}}\right),
$$

where $Q_{\text {meas }}\left(t_{\text {end }}\right)$ is the measured discharge at the end of the recession event and $Q_{\text {recession }}(t)$ is the modelled discharge at any time before the end of the measured event $\left(t_{\text {end }}\right)$. This method has the advantage of not requiring an exact knowledge of when the recession event started.

The fit between measured and modelled discharge in Fig. 2 is very good from 15 November to the end of the record. Before this date, analysis of meteorological data suggests that melt inputs contributed to streamflow in addition to groundwater exfiltration. Records show that substantial snowfall occurred between 28 and 31 October, bringing snow depth at the meteorological station from 0 to $113 \mathrm{~cm}$. Between the last peak discharge (5 November) and mid-November, a rain-onsnow event occurred, which prevented total discharge from representing only baseflow. The entire catchment remained covered by snow and on 11 November, as the air temperature sharply dropped below $0{ }^{\circ} \mathrm{C}$, the snowpack froze and water percolation through the snowpack stopped. Soil moisture in the upper soil layers subsequently dropped and therefore, from 15 November to the end of the record, the observed flow should represent pure recession from the "slow" reservoir.

Our conceptual model presented in the previous section considers that streamflow on 15 November 2008 is only constituted of groundwater flow from the "slow" reservoir. At this date, the "slow" reservoir is full and its discharge is $0.07 \mathrm{~m}^{3} \mathrm{~s}^{-1}$ (Fig. 2, lower panel).

This fixed value denoted baseflow max $_{\text {will represent the }}$ contribution of the "slow" reservoir to streamflow for all subsequent periods during which the "fast" reservoir is not empty.

\subsubsection{Groundwater level in the fast reservoir}

A total of nine groundwater level sensors and four stream stage sensors were installed in the forefield and could be used to compute a groundwater storage function. In order to represent a balanced spatial average of GW levels in the forefield, we used data from the far piezometer of each transect $\left(\mathrm{S} 1_{\text {far }}\right.$, $\mathrm{S} 3_{\text {far }}, \mathrm{S} 5_{\text {far }}, \mathrm{S} 6_{\text {far }}$ and S0). From mid-October onwards, most piezometers were empty except for $\mathrm{S} 6_{\text {far }}$, which some years provided stage data until December. For this reason and because there were other periods during which data from some piezometers were missing, we computed a reservoir function every year as an integral of mean stage variations. For each time step, the integral water level in the reservoir $L_{\text {integral was }}$ implemented as follows:

$\left\{\begin{array}{l}L_{\text {integral }}(t)=L_{\text {integral }}(t-\Delta t)+\sum_{i=1}^{n} \frac{L_{i}(t)-L_{i}(t-\Delta t)}{n}, \\ L_{\text {integral }}\left(t_{\text {end }}\right)=L_{\text {residual }},\end{array}\right.$

where the second term on the right of the main equation is the mean variation in groundwater level between $t-\Delta t$ and $t$, using all available piezometers (a total of $n$ ). This methodology limits measurement noise and creates a continuous storage function as long as one piezometer is available. Without the second equation, the computed reservoir would however only offer a relative value of storage. To correct for this, we assumed that the reservoir drains at the end of each season ( $t_{\text {end }}$; end of October in this case) to a residual water storage volume $L_{\text {residual }}$ which was adjusted for each year. Note that $L_{\text {integral }}(t)$ represents the height of saturated material in the "fast" reservoir. For this reason, the drainable porosity is introduced in the next section.

\subsubsection{Total groundwater flow}

In our model setup, total groundwater flow is the sum of exfiltration from both the slow and fast reservoirs. The slow reservoir is always full when the fast reservoir is not empty, that is, during the main part of the hydrological season (start of June to end of October). It displays a constant exfiltration

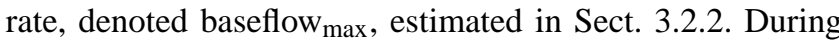
this period, the total groundwater exfiltration flow is obtained by adding the output of both reservoirs using Eq. (4):

$Q_{\mathrm{gw}}(t)=$ baseflow $_{\max }+\frac{A_{\text {fast }} \times L_{\text {integral }}(t) \times \phi}{T_{\text {fast }}}$,

where $T_{\text {fast }}$ is the time constant of the fast reservoir, $A_{\text {fast }}$ is its area and $\varphi$ is the drainable porosity. When the fast reservoir is empty (autumn, winter and beginning of spring), groundwater exfiltration follows Eq. (4).

The model proposed in this study is obtained by integrating Eq. (7) into Eq. (3) via the groundwater component $Q_{\mathrm{gw}}$. In the rest of the manuscript, this will be referred to as the "FULL" model as it uses both electrical conductivity and groundwater data. The complete modelling framework is schematically summarized in Fig. 3. 
Table 3. Calibration of the full model (FULL) and both partial models $\left(P_{\mathrm{EC}}\right.$ and $\left.P_{\mathrm{GW}}\right)$ for four years of data. $P_{\mathrm{EC}}$ uses only electrical conductivity data, whereas $P_{\mathrm{GW}}$ uses only groundwater level data. For each calibration year, validation is performed on all remaining years.

\begin{tabular}{|c|c|c|c|c|c|c|c|c|c|}
\hline & \multicolumn{3}{|c|}{ Relative error (\%) } & \multicolumn{3}{|c|}{$\begin{array}{l}\text { Nash-Sutcliffe } \\
\text { efficiency }\end{array}$} & \multicolumn{3}{|c|}{ Benchmark efficiency } \\
\hline & FULL & $P_{\mathrm{EC}}$ & $P_{\mathrm{GW}}$ & FULL & $P_{\mathrm{EC}}$ & $P_{\mathrm{GW}}$ & FULL & $P_{\mathrm{EC}}$ & $P_{\mathrm{GW}}$ \\
\hline Calib 2009 & 13.3 & 30.6 & 37.3 & 0.78 & 0.44 & -0.18 & 0.49 & -0.30 & -1.73 \\
\hline Valid 2010, 2011, 2012 & 27.4 & 37.3 & 48.8 & 0.58 & 0.29 & -0.39 & 0.09 & -0.55 & -2.06 \\
\hline Calib 2010 & 13.5 & 31.9 & 41.9 & 0.90 & 0.63 & -0.17 & 0.76 & 0.11 & -1.80 \\
\hline Valid 2009, 2011, 2012 & 25.7 & 36.3 & 48.3 & 0.60 & 0.30 & -0.53 & 0.14 & -0.53 & -2.35 \\
\hline Calib 2011 & 19.1 & 33.2 & 42.8 & 0.86 & 0.75 & -0.23 & 0.70 & 0.46 & -1.68 \\
\hline Valid 2009, 2010, 2012 & 42.0 & 54.2 & 51.9 & 0.25 & 0.29 & 0.21 & -0.73 & -0.60 & -0.77 \\
\hline Calib 2012 & 25.7 & 36.3 & 52.9 & 0.64 & 0.21 & 0.01 & 0.25 & -0.64 & -1.05 \\
\hline Valid 2009, 2010, 2011 & 22.5 & 34.7 & 45.7 & 0.72 & 0.48 & 0.04 & 0.36 & -0.17 & -1.18 \\
\hline
\end{tabular}

\subsection{Model calibration and performance assessment}

\subsubsection{Calibrating against total discharge}

The FULL model and two alternative models (named partial models hereafter) each using only one type of field measurement (either EC or GW) were calibrated against measured discharge. The first partial model, denoted $P_{\mathrm{EC}}$, used Eq. (3) with a calibrated constant groundwater exfiltration rate $\left(Q_{\mathrm{gw}}\right)$. Weijs et al. (2013) used this model to calibrate a rating curve using EC rather than stream stage. The second partial model, denoted $P_{\mathrm{GW}}$, had a variable groundwater inflow as per Eq. (6) but used a constant value for EC (yearly average). The aim was to determine whether both electrical conductivity and groundwater data used by the FULL model improved its modelling performance.

The models were calibrated for each full hydrological year (4 years from 2009 to 2012) and validated with the 3 remaining years. Calibration started at the beginning of June and stopped when EC became unavailable, usually mid-October. Relative error was used as a performance measure for calibration. In addition, the Nash-Sutcliffe efficiency (NSE) and benchmark efficiency (BE) were evaluated based on Eq. (8):

Efficiency $=1-\frac{\sum_{t}\left(Q_{\text {meas }}(t)-Q_{\text {mod }}(t)\right)^{2}}{\sum_{t}\left(Q_{\text {meas }}(t)-Q_{\text {bench }}(t)\right)^{2}}$,

where $Q_{\text {meas }}$ is measured discharge; $Q_{\text {mod }}$ is modelled discharge and $Q_{\text {bench }}$ is either runoff predicted by a benchmark model (to compute the $\mathrm{BE}$ ) or by the average of the measured data (to compute the NSE). Our benchmark model uses the discharge value recorded exactly $24 \mathrm{~h}$ earlier, which is a rather stringent test as the signal displays daily fluctuations for much of the hydrological season. Due to the highamplitude seasonal discharge record, the average measured discharge poorly describes the catchment hydrology. For this reason, BE provides a better assessment of model performance than NSE, which is bound to be high.

\subsubsection{Mass balance verification}

Our model so far has not taken into account the infiltration of surface water into the aquifer. Neglecting evapotranspiration and infiltration from the lateral moraines, the difference between surface infiltration and groundwater exfiltration represents the change in groundwater storage in the forefield at every time step. The mass balance equation can be written to express the instantaneous infiltration rate $Q_{\text {inf }}(t)$ as follows:

$Q_{\mathrm{inf}}(t)=\frac{\mathrm{d} V(t)}{\mathrm{d} t}+Q_{\mathrm{gw}}(t)$.

Our calibration procedure only allowed optimizing the fraction $A_{\text {fast }} / T_{\text {fast }}$ without considering the mass balance of the aquifer. Equation (9) shows that infiltration is dependent on $\mathrm{d} V(t) / \mathrm{d} t$ so that rapid variations in modelled groundwater storage could lead to negative and thus unrealistic infiltration. With the constraint that $Q_{\text {inf }}$ may not become negative, Eq. (9) can provide an upper limit to the total volume of the "fast" reservoir because it is directly related to extreme negative values of $\mathrm{d} V(t) / \mathrm{d} t$.

\section{Results}

\subsection{Model calibration against total discharge}

The cross-validation results of the 4 years of data are presented in Table 3. Both partial models $\left(P_{\mathrm{EC}}\right.$ and $\left.P_{\mathrm{GW}}\right)$ were tested and displayed worse performance in all cases. This finding reveals that including both electrical conductivity and groundwater level data benefited the FULL model. Of the two data sources used in the FULL model, EC provides better information for modelling discharge, as model $P_{\mathrm{GW}}$ performed much worse than model $P_{\mathrm{EC}}$. 
Table 4. Calibration and validation results for the FULL model after adjusting for $L_{\text {residual }}$.

\begin{tabular}{lccccc}
\hline & $\begin{array}{c}\text { Relative } \\
\text { error } \\
(\%)\end{array}$ & $\begin{array}{c}\text { Nash-Sutcliffe } \\
\text { efficiency }\end{array}$ & $\begin{array}{c}\text { Benchmark } \\
\text { efficiency }\end{array}$ & $\begin{array}{c}L_{\text {residual }} \\
(\mathrm{mm})\end{array}$ & $\begin{array}{c}\text { Optimal } \\
T_{\text {fast }} \\
\text { (h) }\end{array}$ \\
\hline Calib 2009 & 13.3 & 0.78 & 0.49 & 0 & \\
Valid 2010, 2011, 2012 & 19.5 & 0.8 & 0.57 & - & \\
\cline { 1 - 5 } Calib 2010 & 13.5 & 0.90 & 0.76 & 26 & \\
Valid 2009, 2011, 2012 & 19.4 & 0.76 & 0.48 & - & \\
\cline { 1 - 5 } Calib 2011 & 19.1 & 0.86 & 0.70 & 156 & \\
Valid 2009, 2010, 2012 & 17.5 & 0.78 & 0.51 & - & \\
\cline { 1 - 4 } Calib 2012 & 25.7 & 0.64 & 0.25 & 86 & \\
Valid 2009, 2010, 2011 & 15.3 & 0.85 & 0.51 & - & \\
\hline
\end{tabular}
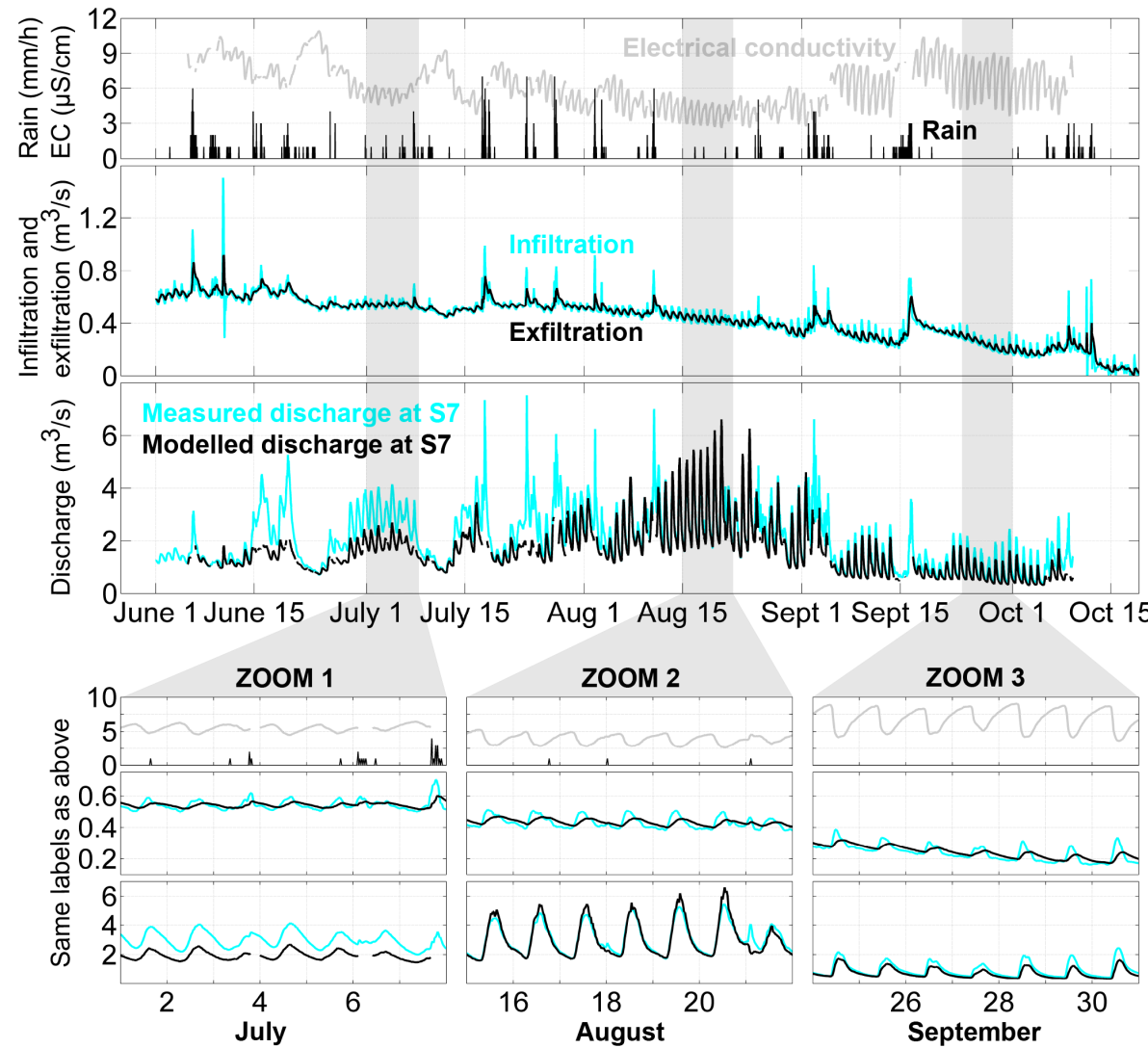

Figure 4. The upper section presents model results for the entire 2009 season. The lower section presents enlargements of 3 specific weeks. For each group of three graphs, the bottom panel displays both measured and modelled discharge $\left(\mathrm{m}^{3} \mathrm{~s}^{-1}\right)$ at $\mathrm{S} 7$. The middle panel presents infiltration and exfiltration $\left(\mathrm{m}^{3} \mathrm{~s}^{-1}\right)$. Electrical conductivity $\left(\mu \mathrm{S} \mathrm{cm}^{-1}\right)$ and rainfall $\left(\mathrm{mm} \mathrm{h}^{-1}\right)$ are plotted in the upper panel. Time periods that were filtered out can be seen as gaps in the EC data (e.g. in zoom 1).

The FULL model's optimal parameter set for the hydrological season of 2011, however, led to significantly worse validation results than the other years. This particular year was characterized by a warm autumn with very late snowfalls. To compensate for year to year variability in residual water content in the fast reservoir at the end of October, we performed some adjustments to $L_{\text {residual }}$. Table 4 presents the improved validation performance of the FULL model with the addition of a residual water content term. Our model presents high and reliable performance, which indicates that the main assumptions are coherent with the physical processes involved. The optimal parameter $T_{\text {fast }}$ was $6.5 \mathrm{~h}$. 
Figure 4 shows the model results for 2009. Daily variations in total discharge are appropriately reproduced, although with some underestimation during most of the early summer (zoom 1). Discharge recessions following two cold snaps around 20 June and 10 July are however accurately modelled. The modelling results significantly improve from the beginning of August onwards, as non-glaciered slopes have become free of snow. Zooms 1 and 3 in Fig. 4 focus on periods of underestimation, whereas zoom 2 illustrates slight peak flow overestimation during intense melt periods. In Sect. 5.4 we suggest that those deficiencies are caused by seasonal variations in the "glacier melt" EC endmember $\left(\mathrm{EC}_{\mathrm{gl}}\right)$.

These results were obtained with a total volume of the "fast" reservoir based on an area $A_{\text {fast }}$ of $1000 \mathrm{~m}$ by $100 \mathrm{~m}$ (approximate length and width of the forefield). This seems a reasonable value as infiltration remains positive throughout the season except in very few instances at the end of the record (Fig. 4). Zooms 1, 2 and 3, show daily cycles in which periods of infiltration and exfiltration dominance (during day and night, respectively) alternate with one another. The proposed size of the "fast" reservoir is at the upper limit for a realistic (non-negative) infiltration. This will be further considered in the discussion.

Figure 5 shows the estimated percentage of groundwater exfiltration as a function of total measured discharge for 2009. Only the best modelled time steps are displayed (less than $10 \%$ absolute error in total discharge). The season starts with medium flow and a high groundwater contribution (snowmelt-dominated in June), then progresses to high flows with a very low groundwater contribution (glaciermelt-dominated in August). The end of the season (September) is characterized by low flows and an increasing groundwater contribution. These qualitative results suggest that the model is appropriately describing exfiltration processes.

\subsection{Verifying $A_{\text {slow }}$ with spring recharge}

The total volume of the "slow" reservoir can be estimated with Eq. (4), using the optimal parameter $T_{\text {slow }}$ $\left(T_{\text {slow }}=29\right.$ days $)$ and the baseflow $\max$ value of $0.07 \mathrm{~m}^{3} \mathrm{~s}^{-1}$. For $1000 \mathrm{~m}$ of length and $400 \mathrm{~m}$ of width, this yields a maximum depth of $1.73 \mathrm{~m}$. The surface of the aquifer was assumed based on topographical data (see Fig. 1) and perceptual understanding of the forefield. Porosity was set to 0.25 , the average of all sites mentioned in Smittenberg et al. (2012).

The aim of Fig. 6 is to illustrate the recharge of the slow reservoir during spring snowmelt. Using Eq. (4) to relate the volume of water in the reservoir $\left(V_{\text {slow }}(t)\right)$ and its exfiltration rate $\left(Q_{\mathrm{gw}}(t)\right)$, and adding a recharge term $R(t)$, the storage function can be expressed as follows:

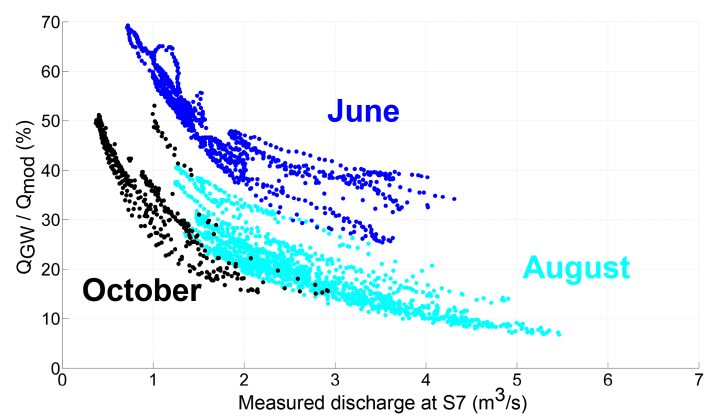

Figure 5. Modelled ratio of groundwater exfiltration to total modelled discharge (in \%) as a function of total measured discharge for 2009. Only time steps with less than $10 \%$ relative error against measured discharge were plotted.

$V_{\text {slow }}(t)=V_{\text {slow }}(t-\Delta t)+\left(R(t)-\frac{V_{\text {slow }}(t-\Delta t)}{T_{\text {slow }}}\right) \times \Delta t$,

where $\Delta t$ is the time step ( $30 \mathrm{~min}$ in our case).

After a 150-day period with little or no recharge (November to end of March), the slow reservoir would come out of winter with only $10 \mathrm{~cm}$ of storage remaining. In Fig. 6, the recharge of the reservoir was simulated using Eq. (10) with a recharge rate of $100 \mathrm{~L} \mathrm{~s}^{-1}$ during every snowmelt period. This rate is equivalent to complete infiltration of $22 \mathrm{~mm} \mathrm{day}^{-1}$ of snowmelt in the forefield. Even though $\mathrm{S}_{\mathrm{far}}$ fills at an early date, for the following interpretation, we retain the conceptual view that the "fast" reservoir starts filling once the "slow" reservoir is full.

The main feature of Fig. 6 is the successive appearance of permanent water in the different piezometers (plotted GW levels are the depth of water in each piezometer). $\mathrm{S}_{\mathrm{far}}$ is located at the lower end of the forefield and is quickly filled by permanent water. $S 1_{\text {far }}$, on the other hand, displays daily peaks for approximately 3 weeks before water permanently rises on 10 May. We suggest that snowmelt regularly fills the piezometers but infiltrates deep into the aquifer through an unsaturated zone because the "slow" reservoir is not yet full. The "slow" reservoir depth is about $1.3 \mathrm{~m}$ when $S 1_{\text {far }}$ permanently fills, whereas its maximum depth was earlier estimated at $1.73 \mathrm{~m}$. This is reasonable because $S 1_{\text {far }}$ is not quite at the highest point of the forefield, and the reservoir may still keep filling under the "dead ice body". This result suggests that if the recharge rate was well estimated, then the reservoir volume too was correctly estimated, providing an independent method to verify the $T_{\text {slow }}$ parameter derived from the 2008 recession analysis.

\section{Discussion}

\subsection{Constraining the fast reservoir volume}

Previous sections presented satisfying total discharge modelling results. Complementary verifications also suggested 
that both groundwater exfiltration rates and the total volume of the "slow" reservoir had been well estimated. Finally, infiltration analysis provided an upper limit on the possible volume of the "fast" reservoir, under the constraint that infiltration may not become negative.

This limit is however directly dependent on the choices made to compute the integrated groundwater level $L_{\text {integral }}$. It is possible that $L_{\text {integral }}$ displayed excessively large daily fluctuations requiring a small "fast" reservoir for infiltration to remain positive. Magnusson et al. (2014) showed that the damping of daily stream stage fluctuations into the aquifer is a significant process influencing groundwater storage. We used the piezometers that were farthest away from the stream for the computation of the reservoir function. However, those piezometers may have been too close to the stream to accurately describe the average storage fluctuations of the aquifer.

We suggest that the absolute depth of this "fast" reservoir is on the order of $1 \mathrm{~m}$ for the following reasons: (i) the maximum value attained by $L_{\text {integral }}$ is $0.9 \mathrm{~m}$ (i.e. the piezometers are on average approximately $1 \mathrm{~m}$ deep), and (ii) most of them are nearly empty by the end of the season (end of October) when the "fast" reservoir has depleted. Based on this depth, the simulations in Fig. 4 were carried out with a "fast" reservoir area $\left(A_{\text {fast }}\right)$ of $1000 \mathrm{~m}$ by $100 \mathrm{~m}$. This corresponds to the length of the forefield by twice the distance from the stream to S0 and is also roughly the average width of the braided river system over the forefield (slightly smaller than the green zone in Fig. 7).

Based on those geometrical aspects, we suggest that the "fast" aquifer is characterized by high hydraulic conductivities, spans the riparian and hyporheic zones of the braided stream network and is on the order of $1 \mathrm{~m}$ deep.

\subsection{Conceptual hydrogeological model of the forefield}

The aim of this section is to propose a conceptual overview of the site's hydrogeology, based on modelling insights and previous results. This is illustrated in Fig. 7.

The modelling chain presented in this study yielded robust simulation of total discharge as a function of groundwater levels in the forefield and stream EC at the discharge station. The model then enabled the estimation of an active groundwater reservoir in the forefield. Based on the initial hypothesis of a combination of two linear reservoirs, we found that the deeper reservoir empties slowly and has a volume equivalent to the area of the forefield $(1000 \mathrm{~m}$ by $400 \mathrm{~m})$ with a depth of $1.7 \mathrm{~m}$ if porosity is assumed constant at 0.25 . A shallower aquifer fills on top of the base aquifer during summer and responds rapidly to daily fluctuations in stream stage.

Geophysical campaigns have however shown that depth to bedrock is likely to be at least $10 \mathrm{~m}$ in most of the forefield (Kobierska, 2014). We can therefore expect part of the saturated sediment volume to act as a non-contributing aquifer, flowing below the discharge station. How much this hidden groundwater flow component affects the yearly water bal- ance would be difficult to assess as total sediment depth and its hydraulic properties are technically challenging to measure. Note that at the beginning of spring snowmelt recharge in 2011 (Fig. 6), modelling shows that the slow "active" reservoir had not completely emptied over the winter before recharge by snowmelt started.

\subsection{Limitations and uncertainties}

One key problem with the use of mixing models in such an environment is the limited range of variation in EC. Also, the recorded values are at the lower end of what can be measured by typical instrumentation. However, the use of 4 years of data defined by strong and consistent daily fluctuations allowed for interesting findings. Brown (2002) highlights that mixing models are not as well adapted to glacial environments as previously thought. In our case, however, the length and high temporal resolution of the time series make the technique worth testing.

Considering hydrology in the forefield as the mixing of only two water sources is clearly a simplification. We can list a total of four components: snowmelt, glacier melt, groundwater exfiltration, and rainwater. Rainfall is hard to quantify due to strong elevation gradients. Had rainfall been known, a three-component mixing model with a rain endmember of $6.05 \mu \mathrm{S} \mathrm{cm}^{-1}$ (Table 2) would not have had a significant impact, since the average measured EC at the discharge station was $6.6 \mu \mathrm{S} \mathrm{cm}^{-1}$. For this reason, as well as the quick routing of rainwater through the catchment due to steep topography, the model performance did not significantly improve with further filtering of rainfall (see the modelling assumptions in Sect. 3.1).

Modelled groundwater exfiltration does not solely describe localized groundwater resurgence via springs. Quick hyporheic exchange must lead to some increase in stream water EC as water flows through the forefield. Those processes are considered as groundwater exfiltration by the model and may represent a significant fraction of groundwater flow in the forefield. Brutsaert (2005) stressed that characterizing a basin as a single lumped unit with basin-scale parameters is a useful concept but has limitations. The heterogeneity between different sections of the aquifer is not taken into account, since the model considers the aquifer as a homogenous body. It is nonetheless noteworthy that our simple model, consisting of only two linear reservoirs and considering only two water sources, reliably reproduced discharge. This suggests that despite its simplicity, the modelling approach provided an adequate description of the catchment's hydrogeology. The rugged topography and heterogeneous soils should lead to non-linear behaviours at a smaller scale. However, as pointed out by Fenicia et al. (2006), groundwater reservoirs at the catchment scale tend to show relatively simple behaviour.

Distributed physically based models could potentially yield better results but they require reliable soil data at high 


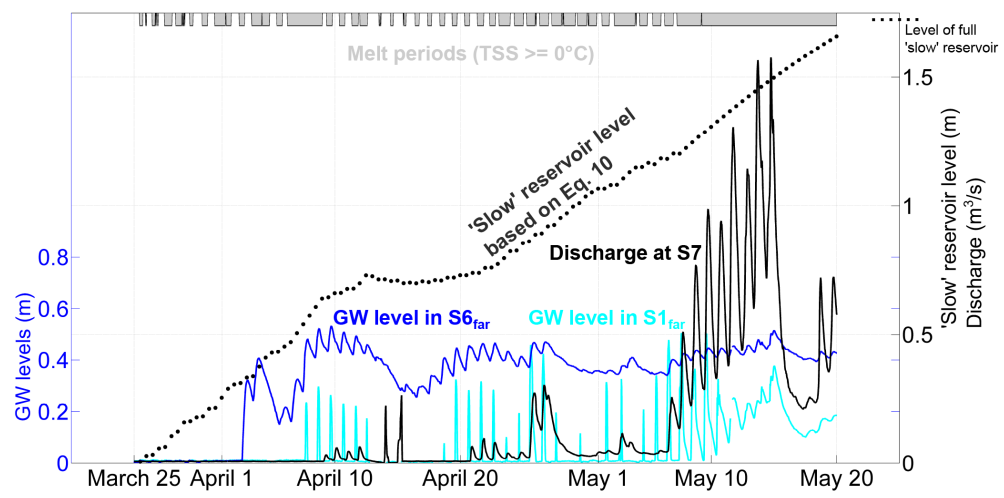

Figure 6. Recharge of the "slow" reservoir from snowmelt in spring 2011. Snowmelt periods (non-negative snow surface temperature) are indicated as grey shading. Groundwater levels, displayed in blue, represent the depth of water in each piezometer. Total discharge and reservoir depth are plotted in black. Reservoir level is computed using Eq. (10) based on a surface area of 400 by $1000 \mathrm{~m}$. The corresponding level of the full reservoir is indicated (dotted line).

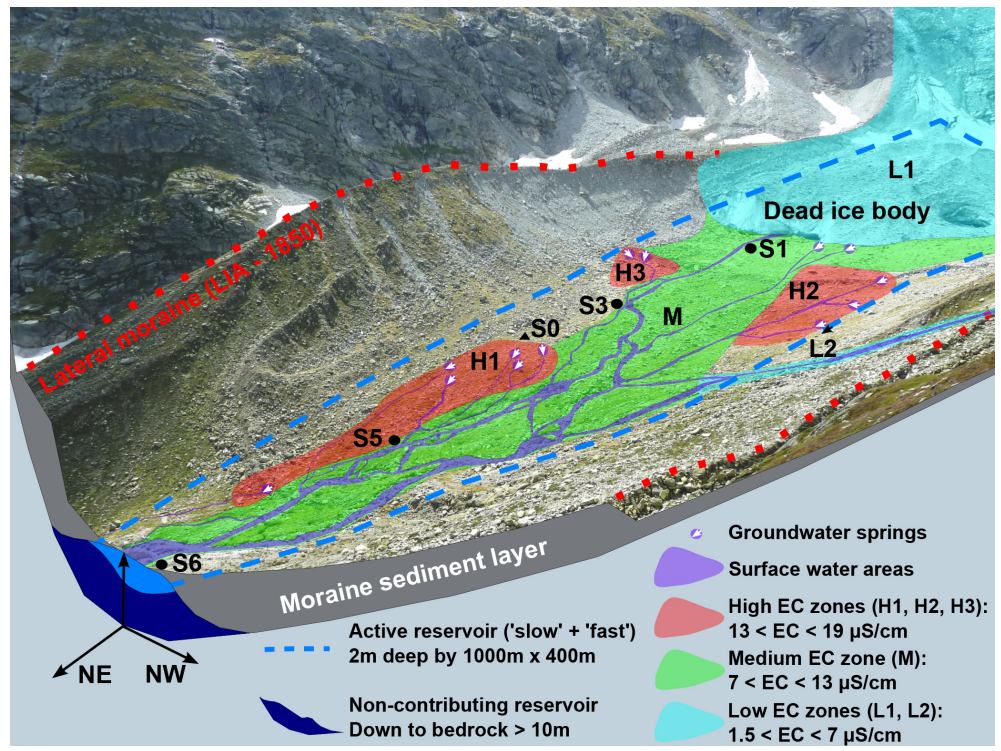

Figure 7. Conceptual summary of the forefield's hydrogeology. The stream network is drawn, as well as the main groundwater springs where electrical conductivity was measured and all electrical conductivity zones. A tentative outline of the active reservoir ("slow" + "fast") is proposed. The discharge station S7 is not displayed as it is slightly outside of the side cut. The lateral moraines are shown by red dotted lines.

spatial resolution. It is typically difficult in alpine catchments to gather such type of data. Obtaining adequate snowmelt and glacier melt data already presents important modelling challenges, as described in previous works at this catchment (Magnusson et al., 2011; Kobierska et al., 2013).

\subsection{Effect of snowmelt and sub-glacial glacier melt}

Every year, the model tended to overestimate total discharge in mid-summer and underestimate it at both ends of the season. At the beginning of the 2009 season (Fig. 4, zoom 1), for instance, discharge is clearly underestimated during high flow spells, whereas mid-August is more correctly modelled
(Fig. 4, zoom 2). As mentioned in the results section, this deficiency is likely due to variations in the "glacier melt" EC endmember. In early summer, this component is actually mainly snowmelt. The difficulty is that snowmelt has a relatively slow release rate and is in direct contact with saturated ground. Snowmelt is thus more likely to infiltrate into soils than glacier melt, leading to intermediate EC values. This had been evidenced in earlier studies such as Sueker et al. (2000).

Peak discharge values were also underestimated in autumn (Fig. 4, zoom 3). The glacier melt endmember may again have been slightly too small. According to Hindshaw et al. (2011), at the end of each season the formation of a 
thin snow cover on the glacier leads to sub-glacial routing of residual glacier melt, in contrast to the fast-flowing melt channels observed during summer (see Fig. 9 in Hindshaw et al., 2011). This implies longer residence times under the glacier, thereby increasing electrical conductivity and leading to underestimation of total discharge.

Hindshaw et al. (2011) had focused on seasonal variations of the contribution of a "sub-glacial component". They, however, termed stream water-groundwater exchanges under the "dead ice body" as sub-glacial, which in our context may be misleading. As mentioned above, we agree with their conclusions that the sub-glacial component changes behaviour during the hydrological season. In our opinion, stream watergroundwater exchanges under the "dead ice body" affect stream water EC more than sub-glacial flow under the bulk of the glacier, which appears to lack a substantial underlying sediment layer.

\subsection{Suggestions for future studies}

Year-round availability of reliable groundwater level data would have been very useful to further test the robustness of this approach. One difficulty in defining the fast reservoir function was indeed the shallowness of most of our piezometers. We lacked an absolute measure of storage during winter and the integral storage function had to be shifted so that the upper fast reservoir emptied to a low residual value at the end of October. This is typically the end of the main hydrological season in high Alpine catchments. As mentioned in the methods, a residual groundwater storage was added to the reservoir for the years that did not display pure recession from the slow reservoir at the end of the calibration period. Groundwater data usually became less reliable in November because potential icing or snow cover affected the atmospheric pressure compensation of the signal. For this reason, the storage calculation was stopped every year at the end of October.

In contrast to EC measurements, isotope ratios have the advantage of being fully conservative. But since the hydrological signal displays daily fluctuations, mixing models would require automated isotope sampling, infrastructure that is both fragile and expensive to install in such a site. Manual oxygen isotope samples (see $\delta^{18} \mathrm{O}$ values in Hindshaw et al., 2011) also showed that groundwater mainly consisted of glacier meltwater. Only in localized areas did heavier isotopes suggest some mixing with rainwater. However, at sites presenting stronger contrasts between rainwater, groundwater and stream water, high-resolution isotope sampling could be of great interest to complement the methodology presented in this study.

To better understand if the assumption of EC as a conservative tracer had an impact on the mixing model, we attempted to measure EC at different locations along the stream. The contrasts were too small to provide reliable insights into the progressive ionic enrichment of stream wa- ter. Such an approach could be interesting in calcareous sites where EC contrasts are usually stronger.

\section{Conclusions}

The main aim of this study was to estimate the contribution of groundwater exfiltration and hyporheic exchange to streamflow at different times of the year in the partly glacierized Damma Glacier catchment in the central Swiss Alps. This site presented experimental challenges specific to alpine areas, making it difficult to collect high-quality data throughout the year. With this study, we improved our understanding of stream water and groundwater interactions during the main hydrological season as well as during winter and early spring.

Our approach builds on previous work which used twocomponent mixing models but did not allow groundwater inflow to vary. We assumed that groundwater exfiltration was produced by the combination of two linear storages. A "slow" reservoir with a response time constant of 29 days was calibrated against a recession event in November 2008. It was overlain by a "fast" reservoir, which was modelled using groundwater level data from five locations in the forefield. Groundwater exfiltration from both reservoirs fed a two-component mixing model whose output was calibrated against measured discharge. The mixing model assumed that stream water was composed of glacier melt and groundwater exfiltration endmembers, which displayed distinct and constant electrical conductivity values.

The model also yielded a realistic volume for groundwater storage actively contributing to streamflow. Our results suggest that the "slow" reservoir spans most of the forefield with an average depth of approximately $1.7 \mathrm{~m}$. The volume of the "fast" aquifer was difficult to estimate but is likely smaller. The "fast" aquifer had a response time constant of $6.5 \mathrm{~h}$, suggesting that it is highly hydraulically conductive and contributes to daily riparian and hyporheic exchanges with the stream.

Modelling assumptions limiting water sources to two endmembers proved consistent with field processes, as the model yielded reliable and reasonable estimates of streamflow. The set of calibrated parameters worked for successive hydrological years marked by climatic variability. In addition, total reservoir volumes and emptying rates were in agreement with previous experimental work carried out at the forefield. This approach provided valuable insights in a difficult alpine catchment and we believe it would be of interest at other sites to infer essential properties of groundwater storage. 
Acknowledgements. Financial support for this study was provided by the SoilTrec project of the European Union FP7 and by the Project BigLink of the Competence Center for Environment and sustainability (CCES) of the ETH Domain. We thank SwissTopo for providing topographical data. Olivier Baffie, Sebastian Würzer and Janet Prevey offered valuable proofreading.

Edited by: G. Fogg

\section{References}

Bernasconi, S. M. and the Big Link consortium: Chemical and biological gradients along the Damma glacier soil chronosequence, Switzerland, Vadose Zone J., 10, 867-883, doi:10.2136/vzj2010.0129, 2011.

Blaen, P. J., Hannah, D. M., Brown, L. E., and Milner, A. M.: Water sources dynamics of high Arctic river basins, Hydrol. Process., 28, 3521-3538, doi:10.1002/hyp.9891, 2014.

Brown, G. H.: Review: glacier melt hydrochemistry, Appl. Geochem., 17, 855-883, 2002.

Brutsaert, W. and Nieber, J. L.: Regionalized drought flow hydrographs from a mature glaciated plateau, Water Resour. Res., 3, 637-643, doi:10.1029/WR013i003p00637, 1977.

Brutsaert, W.: Hydrology: An Introduction, Cambridge Univ. Press, New York, 2005.

Covino, T. P. and McGlynn, B. L.: Stream gains and losses across a mountain-to-valley transition: Impacts on watershed hydrology and stream water chemistry, Water Resour. Res., 43, W10431, doi:10.1029/2006WR005544, 2007.

Dzikowski, M. and Jobard, S.: Mixing law versus discharge and electrical conductivity relationships: application to an alpine proglacial stream, Hydrol. Process., 26, 2724-2732, doi:10.1002/hyp.8366, 2012.

Fenicia, F., Savenije, H. H. G., Matgen, P., and Pfister, L.: Is the groundwater reservoir linear? Learning from data in hydrological modelling, Hydrol. Earth Syst. Sci., 10, 139-150, doi:10.5194/hess-10-139-2006, 2006.

Hannah, D. M. and Gurnell, A. M.: A conceptual, linear reservoir runoff model to investigate melt season changes in cirque glacier hydrology, J. Hydrol., 246, 123-141, 2001.

Hindshaw, R. S. Tipper, E. T., Reynolds, B. C., Lemarchand, E., Wiederhold, J. G., Magnusson, J., Bernasconi, S. M., Kretzschmar, R., and Bourdon, B.: Hydrological control of stream water chemistry in a glacial catchment (Damma glacier, Switzerland), Chem. Geol., 285, 215-230, doi:10.1016/j.chemgeo.2011.04.012, 2011.

Hinton, M. J. and Schiff, S. L.: Examining the contributions of glacial till water to storm runoff using two- and three-component hydrograph separations, Water Resour. Res., 30, 983-993, 1994.

Kobierska, F.: Subsurface hydrology of the Damma glacier catchment: across spatial and temporal scales, $\mathrm{PhD}$ Thesis, Geological Insitute, ETH Zürich, doi:10.3929/ethz-a-010264039, 2014.

Kobierska, F., Jonas, T., Zappa, M., Bavay, M., Magnusson, J., and Bernasconi, S. M.: Future runoff from a partly glacierized watershed in Central Switzerland: A two-model approach, Adv. Water Resour., 55, 204-214, doi:10.1016/j.advwatres.2012.07.024, 2013.
Kobierska, F., Jonas, T., Griessinger, N., Hauck, C., Huxol, S., and Bernasconi, S. M.: A multi-method field experiment to determine local groundwater flow in a glacier forefield, Hydrol. Process., 29, 817-827, doi:10.1002/hyp.10188, 2015.

Kormann, C.: Untersuchungen des Wasserhaushaltes und der Abflussdynamik eines Gletschervorfeldes, Diplomarbeit, Institut für Hydrologie und Meteorologie, Technische Universität Dresden, Dresden, 2009.

Liu, F., Williams, M. W., and Caine, N.: Source waters and flow paths in an alpine catchment, Colorado Front Range, United States, Water Resour. Res., 40, W09401, doi:10.1029/2004WR003076, 2004.

Magnusson, J., Farinotti, D., Jonas, T., and Bavay, M.: Quantitative evaluation of different hydrological modeling approaches in a partly glacierized Swiss watershed, Hydrol. Process., 25, 20712084, doi:10.1002/hyp.7958, 2011.

Magnusson, J., Jonas, T., and Kirchner, J.: Temperature dynamics of a proglacial stream: identifying dominant energy balance components and inferring spatially integrated hydraulic geometry, Water Resour. Res., 48, W06510, doi:10.1029/2011WR011378, 2012.

Magnusson, J., Kobierska, F., Huxol, S., Hayashi, M., Jonas, T., and Kirchner, J. W.: Melt water driven stream and groundwater stage fluctuations on a glacier forefield (Damma gletscher, Switzerland), Hydrol. Process., 28, 823-836, doi:10.1002/hyp.9633, 2014.

Majone, B., Bertagnoli, A., and Bellin, A.: A non-linear runoff generation model in small Alpine catchments, J. Hydrol., 385, 300312, doi:10.1016/j.jhydrol.2010.02.033, 2010.

Rupp, D. E. and Selker, J. S.: On the use of the Boussinesq equation for interpreting recession hydrographs from sloping aquifers, Water Resour. Res., 42, W12421, doi:10.1029/2006WR005080, 2006.

Rupp, D. E., Schmidt, J., Woods, R. A., and Bidwell, V. J.: Analytical assessment and parameter estimation of a lowdimensional groundwater model, J. Hydrol., 377, 143-154, doi:10.1016/j.jhydrol.2009.08.018, 2009.

Smittenberg, R. H., Gierga, M., Göransson, H., Christl, I., Farinotti, D., and Bernasconi, S. M.: Climate-sensitive ecosystem carbon dynamics along the soil chronosequence of the Damma glacier forefield, Switzerland, Global Change Biol., 18, 1941-1955, doi:10.1111/j.1365-2486.2012.02654.x, 2012.

Sueker, J. K., Ryan, J. N., Kendall, C., and Jarrett, R. D.: Determination of hydrologic pathways during snowmelt for alpine/subalpine basins, Rocky Mountain National Park, Colorado, Water Resour. Res., 36, 63-75, 2000.

Tresch, E.: Hydrochemistry of the Damma glacier forefield, Master's Thesis, ETH Zürich, Zürich, 2007.

Weijs, S. V., Mutzner, R., and Parlange, M. B.: Could electrical resistivity replace water level in rating curves for alpine streams?, Water Resour. Res., 49, 343-351, doi:10.1029/2012WR012181, 2013.

Wittenberg, H. and Sivapalan, M.: Watershed groundwater balance estimation using streamflow recession analysis and baseflow separation, J. Hydrol., 219, 20-33, 1999. 